\title{
Confounding variables in studying the effects of maternal alcohol consumption before and during pregnancy
}

\author{
IAN WALPOLE, ${ }^{1}$ STEPHEN ZUBRICK ${ }^{2}$ AND JACQUELINE PONTRÉ ${ }^{3}$ \\ From ${ }^{1}$ the Department of Paediatrics, Princess Margaret Hospital for Children, Perth, Western Australia; \\ ${ }^{2}$ Neurosciences Unit, Health Department of Western Australia; and ${ }^{3}$ the Research and Evaluation Unit, Health \\ Department of Western Australia.
}

\begin{abstract}
Study objective: to investigate the relationship between alcohol consumption and pregnancy outcome.

Design: prospective randomised cohort survey with follow up sample stratified on level of alcohol intake.

Setting: antenatal clinic of large maternity hospital in Western Australia.

Participants: 2002 randomly selected pregnant women recruited over 3 year period for questionnaire survey $(58 \%$ in 1 st trimester, $33 \%$ in 2 nd trimester, $8 \%$ in third trimester at recruitment). Only 19 refused participation. Stratified subsample of 665 women followed up, of whom 60 had miscarriage, stillbirth or neonatal death. Subsample was selected on basis of prepregnancy alcohol consumption. Investigations and main results: All 2002 women completed a comprehensive questionnaire on demographic, lifestyle, health (including diet) and obstetric factors. The stratified subsample was followed through pregnancy and data were collected on obstetric course and infant outcome. Results showed that beer, wine and spirits drinkers differed significantly in maternal characteristics, nutrition and other important variables such as smoking. Women with stillbirths or miscarriages drank more beer than those with live births, though total levels of alcohol intake did not differ. Beer drinkers were less likely to reduce their consumption in pregnancy than other drinkers if they also smoked more than 20 cigarettes per day.

Conclusions: Studies of effects of maternal drinking must include extensive information on the variables examined in this study or conclusions relating to maternal drinking in pregnancy are likely to be invalid.
\end{abstract}

Maternal alcohol ingestion has been implicated as a cause of multiple serious effects on the developing fetus. ${ }^{1-5}$ Social or moderate maternal alcohol intake is said to result in offspring with reduced growth and head circumference, increased rates of neurological abnormalities including intellectual handicap and behavioural disturbance, malformations, prematurity and miscarriages, suggesting there is no safe level of alcohol intake. ${ }^{5-17}$ The most severe end result of heavy, usually chronic, maternal alcohol abuse is the fetal alcohol syndrome. Criteria for diagnosis of this condition include antenatal and postnatal growth failure of proportional distribution, intellectual subnormality, and recognisable facial dysmorphic features such as short palpebral fissures, broad low nasal bridge and a long shallow philtrum. Associated birth defects, particularly of the central nervous, cardiovascular and musculoskeletal systems also occur. $^{1-5}$

Because an alcohol dose threshold for these reported effects is not apparent, several authorities, including the US Surgeon General and the Royal College of Psychiatrists, have advised total avoidance of alcohol by pregnant women. ${ }^{14}$ 18-24 Such statements, issued as a matter of prudence, are not based on conclusive evidence, and are contrary to the findings of some workers. ${ }^{25-31}$

Many of the earlier reports of fetal alcohol syndrome were retrospective and described highly selected populations. Often information was obtained from studies retrospectively or from studies not specifically designed to look at alcohol effects. 
Consequently, alcohol quantification methods were sometimes poor, and usually the type of beverage was not specified, with very little information on diet and insufficient consideration of confounding variables such as socio-economic status, smoking or other substance abuse. ${ }^{1-162728}$

Several animal models for fetal alcohol syndrome have been developed. There is general agreement that high doses of ethanol given to pregnant animals produce toxic fetal effects. These are not found with low alcohol doses, suggesting a threshold effect. ${ }^{32-36}$

The aim of this paper, therefore, was to determine those methodological factors that might bias any of the described effects of light to moderate maternal drinking on pregnancy outcome. An added impetus for this study was the significant public concern about the increasing use of alcohol by young women of child bearing age in this country. ${ }^{37}$

\section{Methods}

\section{SUBJECTS}

Subjects for this study were 2002 pregnant women attending the public antenatal clinic of the main maternity hospital in Western Australia. The women were selected randomly between January 1982 and December 1984 at their first antenatal visit for that particular pregnancy. The majority of women $(58 \%)$ were in the first trimester of their pregnancy at recruitment, $33 \%$ were in the second and $8 \%$ were in their third trimester. We compared our sample with a variety of demographic population characteristics provided by the Australian Bureau of Statistics. The sample contains a higher proportion of single mothers than is typical of the Australian population but otherwise it is indistinguishable from the population of child bearing women in Western Australia in 1981.38

\section{QUESTIONNAIRE}

The questionnaire was of broad scope and consisted of items assessing demographic characteristics, prepregnancy weight and height, and details of previous pregnancies, as well as levels of smoking, consumption of coffee, soft drinks, beer, wine and spirits. Questions on beverages took the form necessary to derive scores on levels of absolute alcohol (AA) consumption per day ${ }^{39}$ and could also be used to derive Calahan's quantitative frequency-volume (QFV) and volume variability (VV) scores. ${ }^{40}$ Women were asked how frequently they drank each category of beverage using forced choice questions with response categories ranging from "never" to "three or more times per day". They were also asked how often they drank each of the quantities " 5 or more", " 3 or 4 " or "1 or 2" glasses. Daily levels of absolute alcohol were derived according to the procedure of Jessor $e t$ $a .^{39}$ Questions on smoking required the women to report how many cigarettes per day they smoked and which brand they usually smoked. Daily intakes of nicotine and tar were then calculated. There were further questions on dietary habits, appetite, number of meals per day, main food items consumed, and frequency and method of cooking. From this information it was possible to derive scores measuring intake of folate and other nutrients.

Medication usage was assessed and medications were divided into major groups. These were: nonnarcotic analgesics; hypnotics and sedatives; indigestion and constipation medications; antibiotics; iron, vitamins and tonics; and nausea control medications.

\section{PROCEDURE}

The questionnaire briefly introduced the aim and purposes of the study without specifically calling attention to alcohol use, and informed the respondents that all answers given were confidential. No verbal direction on how to complete the questionnaire was given, but a study researcher was available to answer questions if necessary and check that forms had been completed. The questionnaire took between twenty and thirty minutes to complete.

The reliability of answers to the smoking and drinking items was assessed by sampling 50 mothers and retesting them within 4-6 weeks of the originako questionnaire. Test-retest reliability (repeatability) coefficients were 0.85 and 0.87 respectively on drinking and smoking items and were deemed acceptable.

\section{IDENTIFICATION OF GROUPS}

Complete clinical and behavioural follow up of mother-baby pairs was intended but with available resources this meant limiting the follow up sample while still ensuring a range of alcohol consumption. Thus from the initial sample of 2002, a subsample of 665 pregnant women, stratified on level of alcohol intake, was drawn. Stratified sampling ensured that the sample included a wide spectrum of drinkers.

Mothers were selected for follow up during confinement and postpartum on the basis of alcohol intake prior to pregnancy rather than during pregnancy or a combination of the two measures. This deliberate decision was based on a number of factors including the often reported decline in maternal alcohol intake during pregnancy, ${ }^{641}$ as was later demonstrated in this study.

In the cohort of 665 pregnant women selected for study, 60 had subsequent outcomes of miscarriage $(n=42)$, still birth $(n=12)$ or neonatal death $(n=6)$. 
Based on alcohol intake, the 665 mother-infant pairs were divided into three groups. Group I $(n=308)$ consisted of women who reported drinking less than $2.8 \mathrm{ml}(0.1 \mathrm{oz})$ of absolute alcohol daily. This group included those who reported no alcohol intake. Group II $(n=265)$ consisted of mothers whose alcohol intake was recorded as between 2.8 and $27.9 \mathrm{ml}$ of absolute alcohol daily $(0 \cdot 1-0.99 \mathrm{oz})$; and Group III $(n=92)$ consisted of those whose alcohol intake was recorded as $28 \mathrm{ml}(1 \mathrm{oz})$ or more daily. Two drinks of spirits, two glasses of wine or two and a half cans of beer contain approximately $28 \mathrm{ml}$ absolute alcohol. ${ }^{40}$ The three groups were called abstainers/light drinkers, moderate drinkers and heavy drinkers respectively.

\section{OBSTETRIC DATA COLLECTION AND INFANT OUTCOME}

Approximately 100 further obstetric factors were then sought for the women of the above groups from hospital records and, when records were inadequate, from further maternal interview. Particular attention was paid to past and current obstetric problems such as miscarriage or bleeding, medical illness such as diabetes, heart disease or infections (18 items), and to intrapartum and postpartum factors. The use of medications such as analgesics, their dosages and their timing were recorded, plus other possible neonatal risks.

Necropsy records for miscarriages, stillbirths and neonatal deaths were examined.

Physical examination was performed by the same paediatrician on all the infants of the cohort. The paediatrician was unaware of the maternal drinking status.

Neurobehavioural assessment was conducted using a slightly modified version of the Albert Einstein neurobehavioural assessment schedule, which is reliable and has been shown to distinguish low birthweight and premature infants from those of normal birthweight and gestation. ${ }^{42}$

Both the physical examination and the neurobehavioural assessment were undertaken between 24 and $72 \mathrm{~h}$ after birth unless the infant was preterm, in which case assessment took place at the appropriate postconceptional age. Infant outcomes will be the focus of a subsequent paper and are not reported here.

\section{Results}

\section{ADEQUACY OF FOLLOW UP SAMPLE}

Several comparisons were made of the characteristics of the 665 mothers selected into the follow up cohort compared with those who were not selected. Significantly more of those followed up were married as opposed to single $\left(\chi^{2}=22.45 ; \mathrm{df}=3 ; \mathrm{p}<0.001\right)$. Otherwise there were no significant differences in maternal height, weight, age, educational level, number of previous pregnancies, rate of cigarette smoking and ethnicity for those chosen for follow up and those not chosen. In addition there were no significant differences in the level of alcohol consumption both before and during pregnancy for the mothers of children followed versus those not followed.

Overall we were satisfied that our sampling procedure yielded a follow up group that was representative of the population of women presenting at a major metropolitan maternity hospital.

CHARACTERISTICS OF LIGHT, MODERATE, AND HEAVY DRINKING WOMEN

Table 1 shows the characteristics of women identified as light, moderate and heavy drinkers before pregnancy. Categorical data were compared using $\chi^{2}$ tests. Analysis of variance (ANOVA) was used for interval level data.

Demographic factors-Moderate and heavy drinkers were significantly more likely to be single, divorced or separated and out of the work force. They were more likely to be living alone or with a boyfriend. Light to moderate drinking was more prevalent in white Australians, while women of European extraction were more likely to be heavier drinkers. Moderate to heavy drinking was significantly associated with higher educational levels. There were no significant differences in parity among the three groups.

Physical characteristics-Moderate and heavy drinkers were taller than light drinkers, but there were no significant differences in mean weight among the three groups. Moderate and heavy drinkers were significantly older than light drinkers.

Diet and smoking-Analysis of variance revealed no significant differences in mean folate scores among the three drinking groups either before or during pregnancy. Moderate and heavier drinkers were significantly more likely to smoke before pregnancy $(50 \%$ and $65.2 \%)$ than were light drinkers $(36.6 \%)$. All groups were more likely to reduce their smoking during pregnancy, but as table 1 shows, the positive association between smoking and alcohol consumption remained.

Medication-We studied the frequency distributions of reported medication by aggregating data under the major group headings, as well as examining the frequency distributions of the subgroups. These distributions took into account the type of medication taken as well as the frequency of usage. 
Table 1 Characteristics of light, moderate, and heavy drinking women ( $n=665)$

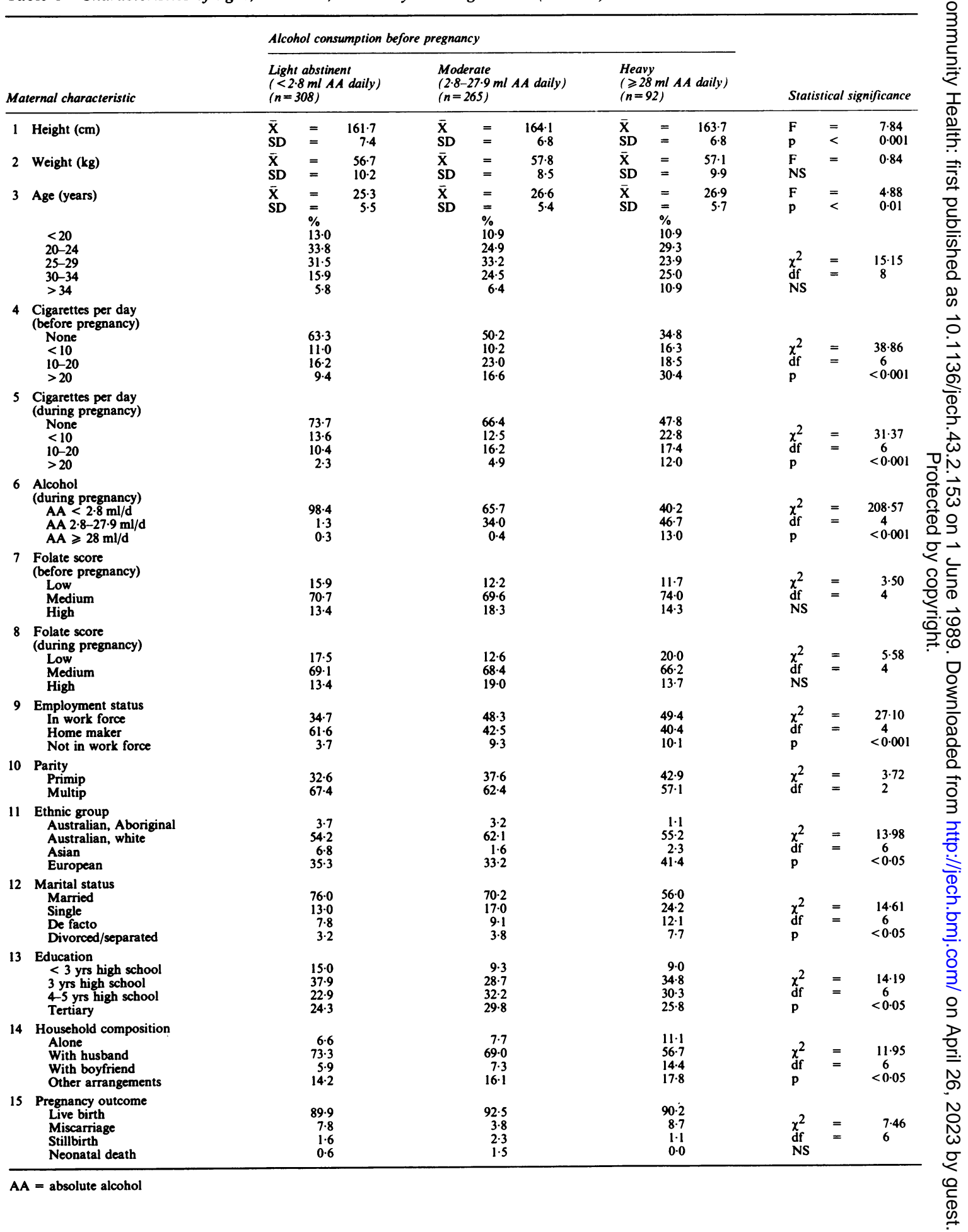


Whilst nearly $30 \%$ of women reported regular analgesic use (paracetamol and/or salicylate), no significant associations between usage of analgesics and alcohol intake or maternal, demographic and lifestyle factors were found.

The remaining categories of drug usage provided us with frequencies that were so small that we could not show any significant associations between their usage and the numerous factors reported above.

Beverages - Consumption of beer, wine and spirits was studied as an independent factor. For each beverage mentioned above, ANOVAs were conducted on the mean absolute alcohol level for groups differentiated by a variety of maternal, demographic and lifestyle characteristics. In this manner we could study the covariation of the type of alcoholic beverage consumed with a range of maternal and demographic variables. Table 2 presents these data.

Beer was consumed more often by unemployed white Australian women either under the age of 25 or over the age of 34 . These women smoked more than 20 cigarettes a day both before and during pregnancy, and were in de facto or divorced circumstances and living with a boyfriend. Unlike wine or spirits drinkers, beer drinkers were less likely to reduce their mean level of absolute alcohol consumption if they smoked more than 20 cigarettes per day.

Wine was consumed more often by women who were characteristically over the age of 30 , of European background, who had had tertiary education, were living alone, and were in the workforce. There was no significant difference in mean absolute alcohol level with level of smoking.

Women who consumed spirits tended to live alone and smoke more than 20 cigarettes a day, but were not distinguished by other factors.

The highest volumes of alcohol were consumed by older women who drank wine, smoked more than 20 cigarettes per day, had tertiary education and were of European background.

OUTCOMES INVOLVING STILLBIRTHS, SPONTANEOUS ABORTIONS AND NEONATAL DEATHS

Sixty women $(9 \%)$ had stillbirths, spontaneous abortions or neonatal deaths.

We compared the 55 women who had spontaneous abortions and stillbirths to those who had livebirths. There were no significant differences in their mean age, height, weight, number of previous livebirths, educational level or ethnic group.

Those women who had stillbirths or spontaneous abortions had a significantly higher mean number of pregnancies compared to women with livebirths $\left(\overline{\mathrm{x}}=2.7 v \overline{\mathrm{x}}=2.2 ; \mathrm{t}_{240}=-2.40, \mathrm{p}<0.01\right)$. They were significantly more likely to be in single or de facto relationships than women whose babies were born alive $\left(\chi^{2}=18.4 ; \mathrm{df}=5, \mathrm{p}<0.01\right)$.

We studied the cigarette and alcohol use in both groups of women for their reported consumption before and during their pregnancy. There was no significant difference in mean cigarette and mean absolute alcohol consumption before and during pregnancy in women who had spontaneous abortion or stillbirths versus those with livebirths ( $t$ test comparison). However, in terms of the pattern of alcohol consumption, we showed in table 2 that women who miscarried drank significantly higher volumes of beer (absolute alcohol intake from beer $=7 \mathrm{ml}$ per day) than those with live births $(3 \mathrm{ml})$ or stillbirth (3ml).

Finally, of the six neonatal deaths, three were males and three were females. Four of these deaths resulted from sequelae of extreme prematurity in infants born at $20,21,23$ and 26 weeks gestation. Of the remaining two deaths, one was due to a group B streptococcal infection, and the other to hydranencephaly.

\section{Discussion}

Of the many epidemiological studies of the effects of maternal drinking on fetal outcome, most do not describe their population broadly or compare it with the general population, so that selected cohorts may be biased. The Seattle study of Streissguth et al $^{43}$ is perhaps an exception, being based on a "non-selected" hospital population (which nonetheless was predominantly white, married and middle class). It was the aim of this present study to look at a cohort which was representative of the moderate social drinking group which comprises the majority of the obstetric population. The aim was achieved with the exception of slight overrepresentation of married mothers.

CHARACTERISTICS OF LIGHT, MODERATE AND HEAVY DRINKING WOMEN

Detailed analysis of the many possible confounding factors in the different alcohol groups is mandatory in attempting to assess a maternal alcohol effect on the fetus. These factors were considered in the study cohort in terms of maternal demographic characteristics, physical characteristics and nutrition, smoking and drug abuse, and type of beverage consumed.

Demographic characteristics-Moderate and heavy drinkers in our sample were more likely to be single, divorced or separated than their lighter drinking peers. This finding is consistent with other studies which also found that alcohol abusing patients were more likely to have been married in the past but less likely to be married during the index pregnancy. 8936 
Table 2 Mean daily alcohol consumption before and during pregnancy for women differentiated by maternal demographic variables, smoking and pregnancy outcome $(n=665)$. Results are $\mathrm{ml}(\mathrm{oz})$ absolute alcohol.

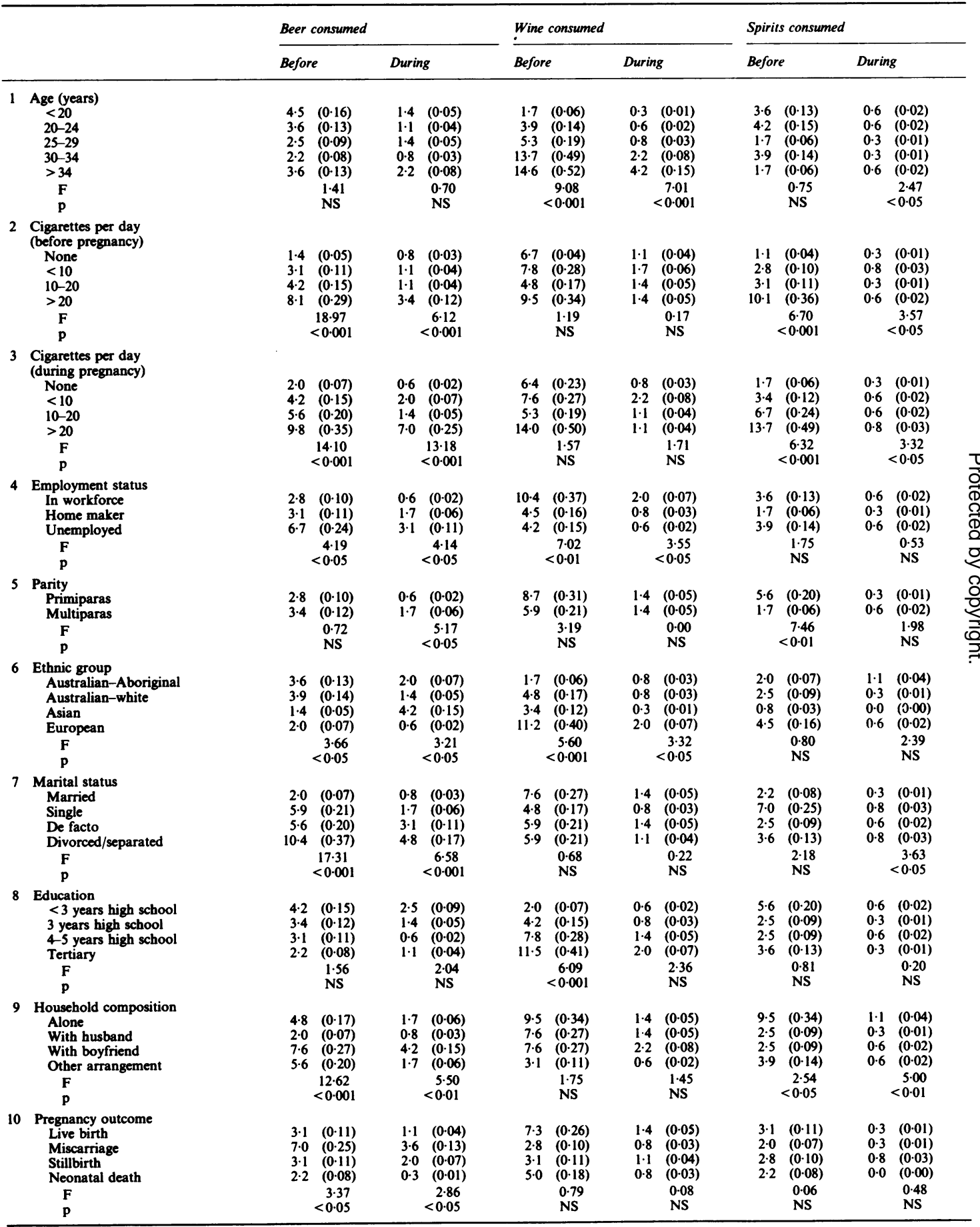


There was a significant trend for those individuals in the regular workforce and with higher education also to be the heavier drinkers, which is contrary to the findings of several other studies. ${ }^{82744}$ In a French study of 18275 pregnant mothers, those who drank more than $400 \mathrm{ml}$ of wine per day were characteristically of lower socio-economic status and not in the work force. ${ }^{8}$ Conversely, in a British cohort of 1256 randomly selected pregnant women, it was found that those who drank most heavily were from social classes I and II. ${ }^{28}$ Similarly in another London study, twice as many women in class I and II (28\%) were relatively heavy drinkers as in classes III-V $(14 \%) .{ }^{15}$ These differences probably reflect important cultural and social characteristics which influence drinking patterns within populations.

Physical characteristics and nutrition-In this study considerable effort went to obtaining details of the maternal diet and its adequacy, and the generation of the folate intake score. It was therefore a very important negative finding that, in general, diets were highly satisfactory throughout the three alcohol groups, and there was no significant difference in mean folate scores for these groups. Similarly, there were no significant maternal weight differences between the groups of mothers.

It is well known that maternal weight prior to and during pregnancy is significantly related to fetal outcome. Women who begin pregnancy with a weight which is equal to or less than $10 \%$ below the standard for height are at greater risk for perinatal mortality and, according to some studies, for intrauterine growth retardation. ${ }^{45} 46$ Various studies have failed to show a consistent correlation between maternal nutrition subsequent psychomotor development. ${ }^{47}$ Alcoholic malnutrition has been associated with maternal zinc deficiency, reported to produce teratogenic effects and reduced birth weight. ${ }^{48}$ Furthermore, one study in mice has suggested that zinc deficiency potentiates the teratogenic effect of alcohol. ${ }^{49}$ Poor nutrition in the alcoholic mother predisposes to higher blood alcohol levels. Weinberg has cautioned that in several animal studies, lack of attention to nutritional status may invalidate the conclusions. ${ }^{32}$

Increased parity has been associated with heavier alcohol intake and increased risk of fetal alcohol syndrome in a number of studies. Later born children of alcoholics are usually more seriously affected than their older siblings. ${ }^{36}$ No differences in parity were observed between the three alcohol groups in this study.

Smoking and drug abuse-That heavier drinkers were significantly more likely to smoke is a finding uniformly consistent with all studies. Similarly, all groups were significantly more likely to reduce their smoking during pregnancy. 44143

Both alcohol use and smoking have been shown to have an effect on birth weight. ${ }^{68915}$ Pregnant heavy drinkers are also more likely than other women to use marihuana $(42.9 \%$ versus $14 \%)$, sedatives, barbiturates, tranquillisers $(13.9 \%$ versus $2 \%)$ and heroin $(1.3 \%$ versus $0.4 \%){ }^{6}$ In one study alcoholics were four times more likely to be narcotic users although the percentage use among alcoholics was relatively low. 9

In our population, rates of drug taking, even of prescribed medications (with the exception of the analgesic and antinausea groups), were generally so low as to be of little statistical significance. In the analgesic and antinausea groups there was no significant association with the alcohol intake groups.

\section{STILLBIRTHS AND SPONTANEOUS ABORTIONS}

In this study, the 55 women who had stillbirths or spontaneous abortions drank significantly higher quantities of beer, although their overall total absolute alcohol levels were not different from those with livebirths. Moderate and heavy maternal drinking before and during pregnancy has previously been associated with increased spontaneous abortion rates. ${ }^{9-11}$ A case-control study of women who aborted spontaneously and women who delivered after at least 28 weeks gestation showed that even moderate consumption of alcohol during pregnancy is a risk factor for spontaneous abortion. ${ }^{11}$ However in the light of our findings the reported differences in spontaneous abortion may not be due to beer consumption but instead reflect other maternal characteristics or variables such as smoking.

\section{BEVERAGE}

Of major interest in this study is the finding that alcohol intake may well be better characterised by analysis of the type of beverage consumed rather than simple absolute alcohol intake. The heavy beer drinker was more likely to smoke more than one pack of cigarettes a day than the wine drinker. Beer and wine drinkers were likely to be of different ethnic origins, marital status, and levels of education and employment (and therefore social class). All these factors have important and different associations with alcohol related disease and fetal outcomes and therefore the relative risks within beverage groups might be expected to be different.

The above observation is important because there have been previous reports, though scant, to suggest that there are differences in perinatal outcome according to preferred beverage. Kuzma $e t a l,{ }^{29}$ in a study of 5093 maternal-infant pairs, showed that the frequency of beer drinking, with wine drinking, spirits 
drinking and other variables, contributed independently to a reduction in intrauterine growth, as measured by birthweight adjusted for gestational age. The study also found that wine and spirits drinking, when considered separately, correlated positively with infant birthweight, in contrast to the negative correlation found with beer drinking.

A population based study of 952 Dundee primigravidas indicated that, on analysis by beverage, mothers drinking beer heavily during the first 4 months of pregnancy had babies of shorter gestational age, lower Apgar scores at 5 minutes and reduced head circumference. Consumption of wine and spirits did not have the same adverse outcome. The authors urged cautious interpretation of the results because of the small number of mothers involved who were heavy beer drinkers. ${ }^{31}$

In a French study of 9236 pregnancies followed through to delivery, birthweight was significantly reduced and the proportion of small for gestational age infants was significantly increased in a subgroup of 158 women who were heavy beer drinkers compared to women who did not drink heavily. Heavy beer drinkers also had an extremely high rate of stillbirths. ${ }^{8}$

Kuzma et al ${ }^{29}$ suggested that beer drinkers, particularly those with chronic alcoholic problems, were more likely to have nutritional deficiencies (for example of zinc) or to be subject to toxic components of beer. This study supports his hypothesis that beer drinkers may have distinctly different demographic, socio-economic and/or medical/obstetric risks from women who drink mainly spirits or wine.

\section{CONCLUSIONS}

This paper reports and comments on the methodology used in a large prospective study of lifestyle variables (including alcohol intake) of a representative sample of a population of pregnant women and details a number of important characteristics related to level of alcohol intake. The most important results were that there were consistent differences in lifestyle and demographic variables for beer, wine and spirits drinkers and that beer drinking women had a poorer pregnancy outcome. A detailed assessment of nutrition showed no significant differences between the prepregnancy alcohol intake of the groups in the study. Our next step will be to analyse the birth outcomes of this sample, allowing for these differences to ensure unbiased interpretation.

We wish to acknowledge the work of Dr Carmen Lawrence in providing this project with initial guidance and support. Our gratitude goes to Ms Sally Mullighan who was instrumental in meticulously gathering the data and assessing the infants. We would like to thank the staff and administration of King
Edward Memorial Hospital for Women, Subiaco, Western Australia, for their full support. We thank Drs Robert Finlay-Jones, Alison Garton and Fiona Stanley for their valued comments.

This research was in part supported by grants from TVW Telethon Foundation and the Princess Margaret Hospital for Children Medical Research Foundation.

Correspondence to Dr Ian Walpole FRACP, Department of Paediatrics, Princess Margaret Hospital for Children, Subiaco 6008, Western Australia.

\section{References}

${ }^{1}$ Hanson JW, Jones KL, Smith DW. Fetal alcohol syndrome, experience with 41 patients. JAMA 1976; 235: 1458-61.

2 Jones KL, Smith DW, Ulleland CN, Streissguth AP. Pattern of malformation in offspring of chronic alcoholic mothers. Lancet 1973; i: 1267-71.

${ }^{3}$ Clarren SK, Smith DW. The fetal alcohol syndrome. $N$ Engl J Med 1978; 298: 1063-7.

${ }^{4}$ Ouelette EM, Rosett HL, Rosman NP, Weiner L. Adverse effects on offspring of maternal alcohol abuse during pregnancy. N Engl J Med 1977; 297: 528-30.

${ }^{5}$ Olegard R, Sabel KG, Aronson M, et al. Effects on the child of alcohol abuse during pregnancy, retrospective and prospective studies. Acta Paediatr Scand Suppl 1979; 279: 112-21.

${ }^{6}$ Little RE. Moderate alcohol use during pregnancy and decreased infant birth weight. Am J Public Health 1977; 67: 1154-6.

${ }^{7}$ Streissguth AP. Fetal alcohol syndrome; an epidemiological perspective. Am J Epidemiol 1978; 107: 467-78.

${ }^{8}$ Kaminski M, Rumeau C, Schwartz D. Alcohol consumption in pregnant women and the outcome of pregnancy. Alcoholism Clin Exp Res; 1978; 2: 155-63.

${ }^{9}$ Sokol RJ, Miller SI, Reed G. Alcohol abuse during pregnancy: an epidemiologic study. Alcoholism Clin Exp Res 1980; 4: 135-45.

${ }^{10}$ Harlap S, Shiono PH. Alcohol, smoking, and incidence of spontaneous abortions in the first and second trimester. Lancet 1980; ii: 173-6.

${ }^{11}$ Kline J, Shrout P, Stein Z, Susser M, Warburton D. Drinking during pregnancy and spontaneous abortion. Lancet 1980; i: 176-80.

12 Sokol RJ, Miller SI, Debanne S, et al. The Cleveland NIAAA prospective alcohol-in-pregnancy study: the first year. Neurobehav Toxicol Teratol 1981; 3: 203-9.

${ }^{13}$ Kaminski M, Franc M, Lebouvier M, Du Mazaubrun C, Rumeau-Rouquette C. Moderate alcohol use and pregnancy outcome. Neurobehav Toxicol Teratol 1981; 3: 173-81.

14 Davis PJM, Partridge JW, Storrs CN. Alcohol consumption, pregnancy and low birthweight. Lancet 1983; i: 664-5.

15 Wright JT, Waterson EJ, Barrison IG et al. Alcohol consumption, pregnancy and low birth weight. Lancet 1983; i: 663-5.

16 Hanson JW, Streissguth AP, Smith DW. The effects of moderate consumption during pregnancy on fetal growth and morphogenesis. J Pediatr 1978; 92: 457-60. 
${ }^{17}$ Landesman-Dwyer S, Keller LS, Streissguth AP. Naturalistic observations of newborns: effects of maternal alcohol intake. Alcoholism Clin Exp Res 1978; 2: 171-7.

${ }^{18}$ Kolata GB. Fetal alcohol advisory debate. Science 1981; 214: 642-4.

${ }^{19}$ Leading Article. Fetal alcohol syndrome. Public Awareness Week Morbidity \& Mortality Weekly Report 1984; 33: 1 .

20 US Surgeon General. Surgeon Generals advisory on alcohol and pregnancy. FDA Drug Bull 1981; 11: 9-10.

${ }^{21}$ Royal College of Psychiatrists. Alcohol and alcoholism. Bull R Coll Psychiatr 1982; 6: 69.

${ }^{22}$ Leading Article. Alcohol and advice to the pregnant women. Br Med J 1983; 286: 247-8.

${ }^{23}$ Annotation. Alcohol and the fetus. Arch Dis Child 1984; 59: 1113-4.

${ }^{24}$ Royal Australian College of Physicians. The position paper on alcohol abuse for the fellows of the College and colleagues throughout the medical profession. Mod Med Aust 1983; 26: 39-40.

${ }^{25}$ Mau G. Moderate alcohol consumption during pregnancy and child development. Eur J Pediatr 1980; 133: 233-7.

${ }^{26}$ Hingson R, Alpert JJ, Day N, et al. Effects of maternal drinking and marijuana use on fetal growth and development. Pediatrics 1982; 70: 539-46.

${ }^{27}$ Tennes K, Blackard C. Maternal alcohol consumption, birthweight and minor physical anomalies. Am J Obstet Gynecol 1980; 138: 774-80.

${ }^{28}$ Grisso JA, Roman E, Inskip H, Beral V, Donovan J. Alcohol consumption and outcome of pregnancy. $J$ Epidemiol Community Health 1984; 38: 232-5.

${ }^{29}$ Kuzma JW, Sokol RJ. Maternal drinking behaviour and decreased intrauterine growth. Alcoholism Clin Exp Res 1982; 6: 396-402.

${ }^{30}$ Mills JL, Graubard BI. Is moderate drinking during pregnancy associated with an increased risk for malformations? Pediatrics 1987; 80: 309-14.

${ }^{31}$ Sulaiman ND, Florey CduV, Taylor DJ, Ogston SA Alcohol consumption in Dundee primigravidas and its effects on outcome of pregnancy. $B r$ Med J 1988; 296: 1500-3.

32 Weinberg J. Nutritional issues in perinatal alcohol esposure. Neurobehav Toxicol Teratol 1984; 6: 261-9.

${ }^{33}$ Sulik KK, Johnston MC, Webb MA. Fetal alcohol syndrome: embryogenesis in a mouse model. Science 1981; 214: 936-8.

${ }^{34}$ Bartley HL, Coyle IR, Singer G. The effects of alcohol induced malnutrition in pregnancy on offspring brain and behavioural development. Pharmacol Biochem Behav 1983; 19: 513-8.

${ }^{35}$ Webster WS, Walsh DA, Lipson AH. Teratogenesis after acute alcohol exposure in inbred and outbred mice. Neurobehav Toxicol Teratol 1980; 2: 227-34.
${ }^{36}$ Abel EL. Fetal alcohol syndrome and fetal alcohol effects. New York: Plenum Press, 1984.

${ }^{37}$ Drew LRH. Changes in Australian drinking patterns: 1969-76. Australian Journal on Alcohol and Drug Dependency 1977; 4: 78-80.

38 Australian Bureau of Statistics Publication. Birth, Australia, Catalogue Number 3301.0, 1981.

39 Jessor R, Graves RD, Hanson RC, Jessor SL. Society personality and deviant behaviour: $A$ study of triethnic community. New York: Holt, Rinehart and Winston, 1968.

${ }^{40}$ Calahan D, Cisin I, Crossley H. American drinking practices: $A$ natural study of drinking behaviour and attitudes. New Brunswick, NJ: Rutger Center of Alcohol Studies, 1969.

${ }^{41}$ Little RE, Streissguth AP. Drinking during pregnancy in alcoholic women. Alcoholism Clin Exp Res 1980; 2: 179-83.

${ }^{42}$ Kutzberg D, Vaughan HG, Daum C, Grellong BA, Albin S, Rotkin L. Neurobehavioural performance of lowbirthweight infants at 40 weeks conceptional age: comparison with normal fullterm infants. Devel Med Child Neurol 1979; 21: 590-607.

${ }^{43}$ Streissguth AP, Martin DC, Martin JC, Barr HM. The Seattle longitudinal prospective study on alcohol and pregnancy. Neurobehav Toxicol Teratol 1981; 3: 223-33.

44 Alpert JJ, Day N, Dooling E et al. Maternal alcohol consumption and newborn assessment: methodology of the Boston City Hospital prospective study. Neurobehav Toxicol Teratol 1981; 3: 195-202.

45 Edwards LE, Alton IR, Barrada MI, Hackanson EY. Pregnancy in the underweight woman: course, outcome and growth patterns of the infant. Am J Obstet Gynecol 1979; 135: 297-302.

${ }^{46}$ Low JA, Galbraith RS, Muir D, Killen H, Karchmar J, Campbell D. Intrauterine growth retardation: a preliminary report of long term morbidity. Am J Obstet Gynecol 1978; 130: 534.

${ }^{47}$ Naeye RL. Maternal nutrition and pregnancy outcome. In: Dobbing J, ed. Maternal nutrition in pregnancy, eating for two? (Nestlé Nutrition Workshop. New York: Academic Press. 1981: 89-111.

${ }^{48}$ Flynn A, Martier SS, Sokol RJ, Miller SI, Golden NL, Del Villano BC. Zinc status of pregnant women: a determinant of fetal outcome. Lancet 1981; i: 572-4

${ }^{49}$ Keppen LD, Pysher T, Rennert OM. Zinc deficiency acts as a co-teratogen with alcohol in fetal alcohol syndrome. Pediatr Res 1985; 19: 944-7.

Accepted for publication December 1988 